\title{
Are societies with a high value on the Active Ageing Index more age-integrated?
}

Pearl A. Dykstra

Department of Public Administration \& Sociology, Erasmus University Rotterdam

\section{Maria Fleischmann \\ Department of Epidemiology \& Public Health, University College London}

Accepted for publication in A. Zaidi, S. Harper, K. Howse, G. Lamura, \& J. Perek-Białas, (Eds.), Building evidence for active ageing policies: Active Ageing Index and its potential.

London: Palgrave McMillan. (January 2017)

\begin{abstract}
Combining round four data from the European Social Survey (ESS) with indicators of Active Ageing, Dykstra and Fleischmann examine conditions conducive to age integration. It uses both a behavioural and an attitudinal measure of age integration: the prevalence of cross-age friendships and low levels of ageism. The analyses focus on both "young" (age 18 to 30) and "old" (ages 70 to 90). Interestingly, high levels of independence, health and security in late life, and greater capacity to actively age rather than high levels of working, volunteering, caring and political engagement among the old create the greatest opportunities for meaningful cross-age interactions. Contrary to public belief, "productive ageing" will in and of itself not lead to greater age integration.
\end{abstract}

\section{Background}

In the literature on cleavages in society, age divides have received less attention than separations by gender, race, social class, or religion. Notwithstanding heated disputes on the generation gap in the 1970s (e.g. Mead 1970), speculations about impending age wars in the 1980s (e.g. Longman 1986), and conjectures in the most recent decades regarding competition between the young and the old over scarce resources (Emery 2012), researchers have not typically focused on age in analyses of social segmentation. We argue that the separation of age groups in ageing societies merits more systematic attention because it restricts individuals to meet, interact and move beyond stereotyped views.

Hagestad and Uhlenberg $(2005 ; 2006$; Uhlenberg 2000) use the term "age segregation" for the separation of children and young adults into schools, the separation of adults into workplaces 
that exclude the young and the old, and the separation of older people out of the workplace and, in some cases, into institutional housing and care arrangements. Leisure-time activities of young and old tend to occur in different locations because they are often organized by age (Hagestad $\&$ Uhlenberg 2005). According to Coleman (1982), age segregation deprives the young of a proper view of mid-life and old age, and produces adults who have little experience with and understanding of the young. The author also argues that age segregation can be an antecedent as well as a consequence of ageism, defined as prejudice by members of one age group against another age group (Butler 1969).

Integration by age occurs when individuals of different ages occupy the same space and hence can engage in face-to-face interactions (Vanderbeck 2007). Lowering age barriers and increasing cross-age interaction may be an effective way of reducing social segmentation and thus promoting more inclusive societies (Hagestad \& Uhlenberg 2005; 2006). Uhlenberg (2000) suggests that some societies may be more age-integrated than others. In his view, researchers need to consider the extent to which formal and informal barriers restrict opportunities for individuals of different ages to mingle, socialize, collaborate, learn, and worship together. We aim to find out whether societies where older adults are visible and active participants (and thus have a high value on the Active Ageing Index (AAI) as developed by Zaidi and colleagues, 2013) are more age-integrated. We use both a behavioural and an attitudinal measure of age integration: the prevalence of cross-age friendships and low levels of ageism. The underlying argument is that high-AAI countries enable durable interactions between young and old, thereby promoting a better understanding of people of different ages.

We use data from the fourth round of the European Social Survey (ESS), which had a special module on "Age attitudes and experiences of ageism", and combine them with indicators of Active Ageing.

\section{Conditions for cross-age interaction}

\subsection{Laws and policies}


National policies geared towards services, financial entitlements, and amenities for specific age groups are examples of societal forces structuring opportunities and constraints for cross-age interactions. Such policies not only serve to distance specific age groups (e.g., placing older adults in residential facilities; separating children and young adults into schools), but might also shape how age groups perceive one another. Binstock (1983) introduced the term "compassionate ageism" to describe how policies reflect or encourage the view that specific age groups have needs that deserve being cared for. Later, Binstock (2010) referred to "doubleedged" compassionate ageism: economically assisting older adults is apparently generous, but also reinforces negative stereotypes of frailty, poverty and dependency.

Legislation defining the rights and duties of members of different age groups is a second example of the macro-level organization of age relations. Age discrimination laws reflect dominant values about "proper" age relations. Generally speaking, it is safe to posit that crossage interactions are more likely in a country that promotes equal treatment of all ages. Nondiscrimination by age became legally enforceable in the European Union in 2006 (Lahey 2010). Some member states have only recently implemented the strand of the Framework Directive prohibiting age discrimination, whilst others have longstanding age discrimination laws. Although these laws have many similarities, there is diversity in prohibitions and enforcement mechanisms.

This brief overview highlights the complexity of delineating policy and legal influences on age integration. For that reason, we decided to focus on the Active Ageing Index rather than legislation and policies. The AAI is a tool that acknowledges that individuals live in a world of multiple jurisdictions and are affected by multiple policies at once (cf. Campbell 2012). Given its focus on the outcomes of and capacities for the participation of older adults in society (Zaidi et al. 2013), the AAI provides an accumulated appraisal of the ways in which policies and laws produce and reflect age barriers. We argue that high-AAI countries have created conditions that promote cross-age interaction. The literature on personal relationships provides clues as to what these conditions might be.

\subsection{Settings}


A key principle of the research on personal relationships is that there is "no mating without meeting" (Blau 1977): people find friends and partners among those they encounter in the course of their daily activities. The meeting principle emphasizes that social settings offer opportunities to meet particular categories of individuals and thereby influence the kinds of personal relationships that develop. Applied to age integration, this principle suggests that those who can draw upon an age-diverse pool of ties are more likely to engage in cross-age interaction.

What settings provide an age-diverse pool of social personal ties? Hagestad and Uhlenberg (2005) argue that "the family represents the only truly age-integrated social institution" (p. 354, emphasis in original). Examples of settings outside the family where old and young can meet and interact are religious communities (Grefe 2011), work (Uhlenberg 2000), volunteer work (Uhlenberg \& De Jong Gierveld 2004), and neighbourhoods (Vanderbeck 2007). Few scholars have examined whether age-integrated settings actually facilitate the formation and maintenance of cross-age ties.

Our first hypothesis is that high AAI-countries are more likely to provide settings enabling durable cross-age interaction than low AAI-countries. The settings we consider are: family, paid work, volunteer work, and religious organizations. Next, for both young and old, we test a second hypothesis: those whose daily activities are in settings enabling durable cross-age interaction are more likely to report cross-age friendships than those whose daily activities do not bring them to such settings.

\subsection{Controls}

Gender differences in personal networks vary by age, life stage, and marital history (e.g., Ajrouch, Blandon \& Antonucci 2005). That is why we introduce controls for gender, age, and partner status in the analyses. We also control for self-reported health given the role possibly played by selection: health status can contribute to the creation or dissolution of specific network ties or to the formation of networks with particular features (Smith \& Christakis 2008).

\section{Cross-age interaction and ageism}


When ageism was first defined (Butler 1969), the phenomenon was viewed as something directed at old people only. By now, researchers acknowledge that ageism goes both up and down generational lines (North \& Fiske 2012). There is a wealth of evidence showing that building sustained familiarity with individuals across social categories is the safest route for breaking down prejudice, overcoming stigma, and preventing discriminatory behaviors (Pettigrew \& Tropp 2006). Empirical support for the notion that cross-generational experiences are generalised to age groups as a whole comes from studies of grandparenthood. Higher levels of quality of contact with grandparents are associated with more positive feelings toward older people in general (e.g., Harwood et al. 2005). Acknowledging that durable interactions with people of different ages foster mutual understanding, we test a third hypothesis: the young and old who report cross-age friendships are less ageist than those who do not report having crossage friendships.

\section{Method}

\subsection{Data}

The fourth round of the ESS was collected in 2008-2009 in 31 countries, of which 25 are EU countries (Italy, Malta and Luxembourg do not participate in the ESS). Our analyses are based on these 25 EU countries (see Table 1 for an overview). We used the AAI-2010, which is based on 2008 data. We restricted the analyses to two age groups. The "young" are respondents aged 18 to 30 ; the "old" are respondents aged 70 to 90 .

\subsection{Measures}

The number of cross-age friendships was measured by asking "About how many friends, other than members of your family, do you have who are [younger than 30/aged over 70]?”. Answer categories ranged from "none" (1) to "10 or more" (5). The variable was dichotomized, assigning respondents the value one when they had two or more cross-age friendship. Sample sizes for the analyses of cross-age friendships are 8716 (young) and 6697 (old). 
To assess ageism, we used the following question: "Tell me overall how negative or positive you feel towards people in their 20s [people over 70]?”. Answer categories ranged from "extremely negative" (0) to "extremely positive" (10). We reverse coded the answers, so higher scores indicate higher levels of ageism. In the multivariate analyses we used the log of the ageism score because responses were heavily skewed. Sample sizes for the analyses of ageism are 8612 (young) and 6512 (old).

We had a set of dummy variables representing settings enabling cross-age interaction. The first was whether the younger [older] adult had any household member aged 70 and older [aged 18 to 30] (1=yes). Moreover, we included whether the younger adult [the older adult] had any family member over 70 [any children or grandchildren] with whom they were able to discuss at least "a few personal issues such as feelings, beliefs or experiences" (1=yes). We also considered whether the respondent attended religious services at least monthly ( $1=\mathrm{yes})$. Another variable indicated whether respondents had done paid work, volunteer work, or both in the last month ( $1=\mathrm{yes})$. To provide an indication of the age composition of the work settings, we added a variable assessing whether respondents spent some, most or (almost) all of that time working with colleagues or volunteers in their 20s [or aged over 70] (1=yes).

The 2010 values for the overall $A A I$, as well as those for the separate indicators were taken from the publicly available AAI website. ${ }^{1}$ Each of the indicators is expressed in percentage terms $(0$ 100). Note that upper goalpost of 100 should not be equated with the optimum, as it represents utopian circumstances of fullest possible active ageing (Zaidi et al. 2013). The separate indicators are: employment; participation in society; independent, healthy and secure living; and capacity and enabling environment for active ageing. All AAI measures were centered on their mean to allow a meaningful model interpretation.

We used four control variables for respondents' gender ( $1=$ female), age (in years), partner status (1=lives with a partner), and health status, respectively. Health status was measured by asking "How is your health in general?". Answer categories ranged from "very good" (1) to "very bad" (5). We reverse coded the responses so higher scores indicate better health.

\footnotetext{
${ }^{1} \mathrm{http} / /$ www1.unece.org/stat/platform/pages/viewpage.action?pageId=76287845
} 


\subsection{Analytical strategy}

We carried out separate analyses for the two age groups under consideration. First, the individual-level data on settings enabling cross-age interaction were aggregated to the country level in order to determine with Pearson's correlations whether high AAI-countries are more likely to provide conditions encouraging interactions between young and old. Second, we used multilevel logistic regression models to analyse the likelihood of having two or more cross-age friends, and multilevel linear regression models to analyse ageism. The same set of country-level and individual-level determinants was included in both models - with one exception: having cross-age friends was added to the analysis of ageism.

\section{Results}

Across all countries, the young are less likely than are the old to report having two or more cross-age friends, $18 \%$ and $31 \%$ respectively. The proportion of young adults reporting crossage friendships is lowest in Lithuania (4\%) and highest in Ireland (36\%) (see Figure 1). The proportion of older adults reporting cross-age friendships is lowest in Lithuania (6\%) and highest in Finland (50\%).

Europeans, both young and old, express few negative feelings about age groups different from their own. On a scale from 0 to 10, the average ageism score across all countries is 2.7 for the young, and 3.1 for the old. Older people are generally somewhat more ageist towards the young, than the young are towards the old. Ageism levels vary little across countries (see Figure 2). Ageism of young towards old is lowest in Finland (1.9), and highest in Slovakia (3.7). Ageism of old towards young is lowest in Greece (2.0), and highest the highest in the UK (4.0).

\subsection{AAI and settings enabling cross-age interactions}

As predicted (see Table 1), we find strong and positive correlations between overall AAI scores and the proportion of people (both young and old) who report engaging in paid or volunteer work 
and who report working with colleagues or volunteers who differ in age by several decades. Overall AAI scores are also strongly and positively correlated with the proportion of younger adults who engage in personal disclosure with older family members. Contrary to predictions, strong negative associations with overall AAI scores are observed for intergenerational coresidence (among both young and old), for religious engagement (among both young and old), and for the proportion of older adults engaging in personal disclosure with a (grand)child. An inspection of the findings for the separate Active Ageing indicators reveals that the employment rates of older adults show no associations with the aggregated measures of the settings enabling cross-age interaction, whereas social participation generally shows moderate associations. The independent, healthy and secure living indicator and the capacity and enabling environment indicator show the strongest associations with the settings enabling cross-age interaction. Summarizing, our first hypothesis receives mixed support.

\subsection{Determinants of cross-age friendships}

Table 2 shows, in accordance with hypothesis 2, that the young whose daily activities bring them to settings enabling cross-age interaction have a higher probability of reporting at least two cross-age friendships. There is one exception: having performed paid and/or volunteer work in the past month is not associated with a higher likelihood of having cross-age friends. The young who share a household with someone over the age of 70 have a factor 1.4 higher odds of reporting cross-age friendships, whereas those who have a family member over the age of 70 with whom personal issues can be discussed have a factor 1.7 higher odds of reporting cross-age friendships. Although having done paid or volunteer work per se is not associated with having cross-age friends, having worked with colleagues or volunteers in their 70 s is a strong predictor: respondents' odds of having cross-age friendships are a factor 2.7 higher. For the young, the odds of reporting cross-age friendships are a factor 1.6 higher when they attend religious services at least monthly.

Among the older respondents, the individual-level determinants of having cross-age friends are quite similar to those for the young. Again, having worked with colleagues or volunteers quite different in age than oneself strongly increases the likelihood of reporting cross-age friendships 
(a factor 2.1 higher). Older respondents living with people under the age of 30 and those who attend religious services at least monthly have a factor 1.4 higher odds of reporting at least two friends under 30, keeping other variables constant. Contrary to what was observed for the younger respondents, having done (volunteer) work is associated with having cross-age friendships (the odds are a factor 1.4 higher). Having a younger family member with whom personal issues are discussed also increases the odds of having cross-age friendships by a factor of 1.1 .

The intra-class correlations in Tables 2 and 3 suggests that about 6-7\% of the variance in crossage friendships is attributable to cross-country differences. As the top right-hand part of Table 3 shows, the overall AAI accounts only for a small part of the cross-country difference. When included to the baseline model, the intra-class correlation decreases by about one percent. Furthermore, the table shows that the effect of the overall AAI is actually attributable to two separate indicators: independent, healthy and secure living, and capacity to actively age. As the bottom right-hand part of Table 3 shows, after controlling for the individual-level predictors, the coefficients for the AAI predictors lose their significance. None of the Active Aging indicators is a significant predictor of the likelihood of having cross-age friendships among the young. Tables 1 and 3, taken together, suggest that the high AAI-countries have settings outside the household enabling cross-age interaction, which in turn facilitate the formation and maintenance of crossage friendships by older adults in particular.

\subsection{Cross-age friendship and ageism}

As predicted, those who report cross-age friendships tend to be less ageist (Table 4). This finding holds for both young and old. The intra-class correlations show that approximately $5 \%$ of the variance in ageism of young towards old, and approximately $10 \%$ of the variance in ageism of old towards young is attributable to cross-country differences. Nevertheless, none of the AA indicators contribute to an explanation of ageism over and above the individual-level indicators (table not shown). 


\section{Conclusion}

The starting point of our study was to find out whether societies where older adults are visible and active can be characterized as more age-integrated in the sense that close ties between the young and the old are not limited to the family, and that both the young and the old tend not to be prejudiced towards one another. The answer to the question of whether societies with a high value on the AAI are more age-integrated is "yes" and "no". A complex pattern emerges from our findings.

First, our study underscores the importance of anchoring, that is, of distinguishing the age group under consideration. A strength of our study is that we focused on both young and old. Whereas none of the AA indicators significantly predicted whether or not younger adults had cross-age friendships, they made a slight difference regarding the likelihood that older adults had cross-age friendships. Older adults were more likely to engage in friendly relations with young individuals in societies with the following characteristics: high levels of independence, health and security in late life, and greater capacity to actively age. These findings suggest that quality of life, wellbeing and autonomy contribute to a general atmosphere facilitating sustained familiarity of the old with the young.

Second, the AAI indicators did not account for any between-country variance in ageist tendencies among either young or old. Conceivably, the cultural climate of a country is more pertinent to the explanation of ageism. The importance of emotional and cultural dispositions is evident at the individual level. Those who have a close relationship with a family member who strongly differs in age tend to be less ageist.

Third, high AAI countries generally offer work-related (both paid and unpaid) settings enabling durable cross-age interaction, but tend to have low levels of household-related (intergenerational co-residence) and religious settings that encourage meaningful contacts between young and old. The individual-level data show that sharing a household with a person who strongly differs in age and frequently attending religious services are conducive to the formation and maintenance of cross-age friendship. Such opportunities are greater in low AAI countries than in high AAI countries. 
We cannot rule out the possibility that the low degree of variance at the country level in the prevalence of friendships and ageist tendencies is responsible for the dearth of significant findings for the Active Ageing indicators. Our individual-level hypotheses received strong support, however. We convincingly demonstrated that people whose daily activities are in settings encouraging cross-age interaction are more likely to have cross-age friends. Previously, few studies have addressed the issue of where, when and how cross-age ties are formed and maintained. This issue has received little attention (Riley \& Riley 2000), perhaps because homophily, the tendency to form relationships with similar others, is a strong theme in relationship research. We also received credible evidence supporting the hypothesis that people with cross-age friendships tend to be less ageist.

Interestingly, the AA indicators representing older adults' activities, i.e. employment and social participation, showed no associations with their likelihood of having cross-age friendships. It seems that we should be cautious to equate high levels of active engagement among the elderly with ample opportunities to encounter young people and to become connected to them. Older adults seem to be primarily active in age-homogeneous ghettos. Our findings suggest that “productive ageing” (e.g., Gonzales, Matz-Costa \& Morrow-Howell 2015) will in and of itself not lead to greater age integration.

Following the adage that societal ageing is not only about older adults, we included both young and old in our study. Interesting contrasts between the two groups emerged. Lower proportions of the young reported cross-age friendships. Moreover, they were generally less prejudiced towards older people than the old were towards younger people. At first sight, this seem contradictory: fewer cross-age friends, but less ageist. However, it is important not to confuse macro-level and micro-level associations. At the individual level, our findings show the expected pattern for both young and old: those who report cross-age friendships tend to be less ageist. One should also note that different target groups are being compared: the young are evaluating the old, whereas the old are evaluating the young. We have no information about how the young feel about their age group and neither do we know how the old feel about their peers. So our findings do not allow assessments about which group is most ageist. Finally, contemporary circumstances of the young require consideration. In their study, Smith, McPherson, and Smith-Lovin (2014) argue that in the US the young increasingly face institutional barriers to engage in cross-age ties. 
They attribute the growing isolation of the young from older cohorts outside of the family to the growing importance of delayed life course transitions. The authors touch upon an issue that is critical in Europe given the current economic crisis: the inability of younger adults to start a life of their own and to enter environments that are less age-homogeneous than the worlds of education and recreation.

\section{References}

Ajrouch, KJ, Blandon, A \& Antonucci, TC 2005, 'Social networks among men and women: The effects of age and socioeconomic status', Journal of Gerontology: Social Sciences, vol. 60, pp. 311-317.

Binstock, RH 1983, 'The aged as a scapegoat', The Gerontologist, vol. 23, pp. 136-143.

Binstock, RH 2010, '50th anniversary feature article. From compassionate ageism to intergenerational conflict?', The Gerontologist, vol. 50, pp. 574-585.

Blau, PM 1977, Inequality and heterogeneity: A primitive theory of social structure, Free Press, New York.

Butler, RN 1969, 'Age-ism: Another form of bigotry', The Gerontologist, vol. 9, pp. 243-246.

Campbell, AL 2012, 'Policy makes mass politics'. Annual Review of Political Science, vol. 15, pp. 333-351.

Coleman, JS 1982, The asymmetric society, Syracuse University Press, Syracuse, NY.

Emery, T 2012, 'Intergenerational conflict: Evidence from Europe', Journal of Population Ageing, vol. 5, pp. 7-22.

Gonzales, E, Matz-Costa, C \& Morrow-Howell, N 2015, 'Increasing opportunities for the productive engagement of older adults: A response to population aging', The Gerontologist, vol. 55 , pp. 252-261.

Grefe, D 2011, 'Combating ageism with narrative and intergroup contact: Possibilities of intergenerational connections', Pastoral Psychology, vol. 60, pp. 99-105.

Hagestad, GO \& Uhlenberg, P 2005, 'The social separation of old and young: A root of ageism', Journal of Social Issues, vol. 61, pp. 343-60.

Hagestad, GO \& Uhlenberg, P 2006, 'Should we be concerned about age segregation? Some theoretical and empirical explorations', Research on Aging, vol. 28, pp. 638-653 
Harwood, J, Hewstone, M, Paolini, S \& Voci, A 2005, 'Grandparent-grandchild contact and attitudes toward older adults: Moderator and mediator effects', Personality and Social Psychology Bulletin, vol. 31, pp. 393-406.

Lahey, JN 2010, 'International comparison of age discrimination laws', Research on Aging, vol. 32, pp. 679-697.

Longman, P 1986 'Age wars: The coming battle between young and old', The Futurist, vol. 20, pp. $8-11$.

Mead, M 1970, Culture and commitment: A study of the generation gap. Wiley, New York.

North, MS \& Fiske, ST 2012, 'An inconvenienced youth? Ageism and its potential intergenerational roots’, Psychological Bulletin, vol. 138, pp. 982-997.

Pettigrew, TF \& Tropp, LR 2006, 'A Metaanalytic test of intergroup contact theory', Journal of Personality and Social Psychology, vol. 90, pp. 751-783.

Riley, MW \& Riley, JW Jr 2000, 'Age integration: Conceptual and historical background', The Gerontologist, vol. 40, pp. 266-270.

Smith, JA, McPherson, M \& Smith-Lovin, L 2014, 'Social distance in the United States: Sex, race, religion, age, and education homophily among confidants, 1985 to 2004', American Sociological Review, vol. 79, pp. 432-456.

Smith, KP \& Christakis, NA 2008, 'Social networks and health', Annual Review of Sociology, vol. 34, pp. 405-429.

Uhlenberg, P 2000, 'Why study age integration?', The Gerontologist, vol. 40, pp. 276-81.

Uhlenberg, P \& De Jong Gierveld, J 2004, 'Age-segregation in later life: An examination of personal networks', Ageing and Society, vol. 24, pp. 5-28.

Vanderbeck, RM 2007, 'Intergenerational geographies: Age relations, segregation and reengagements', Geography Compass, vol. 1/2, pp. 200-221

Zaidi, A, Gasior, K, Hofmarcher, MM, Lelkes, O, Marin, B, Rodrigues, R, Schmidt, A, Vanhuysse, P \& Zolyomi, E 2013, Active Ageing Index 2012: Concept, Methodology and Final Results, EC/UNECE, Active Ageing Index Project, UNECE Grant ECE/GC/2012/003, European Centre for Social Welfare Policy and Research, Vienna. Available from:

$<$ http://www.euro.centre.org/data/aai/1253897823_70974.pdf 
Figure 1. Prevalence of cross-age friendships, 25 EU countries.

\section{$\geq 2$ cross-age friends}

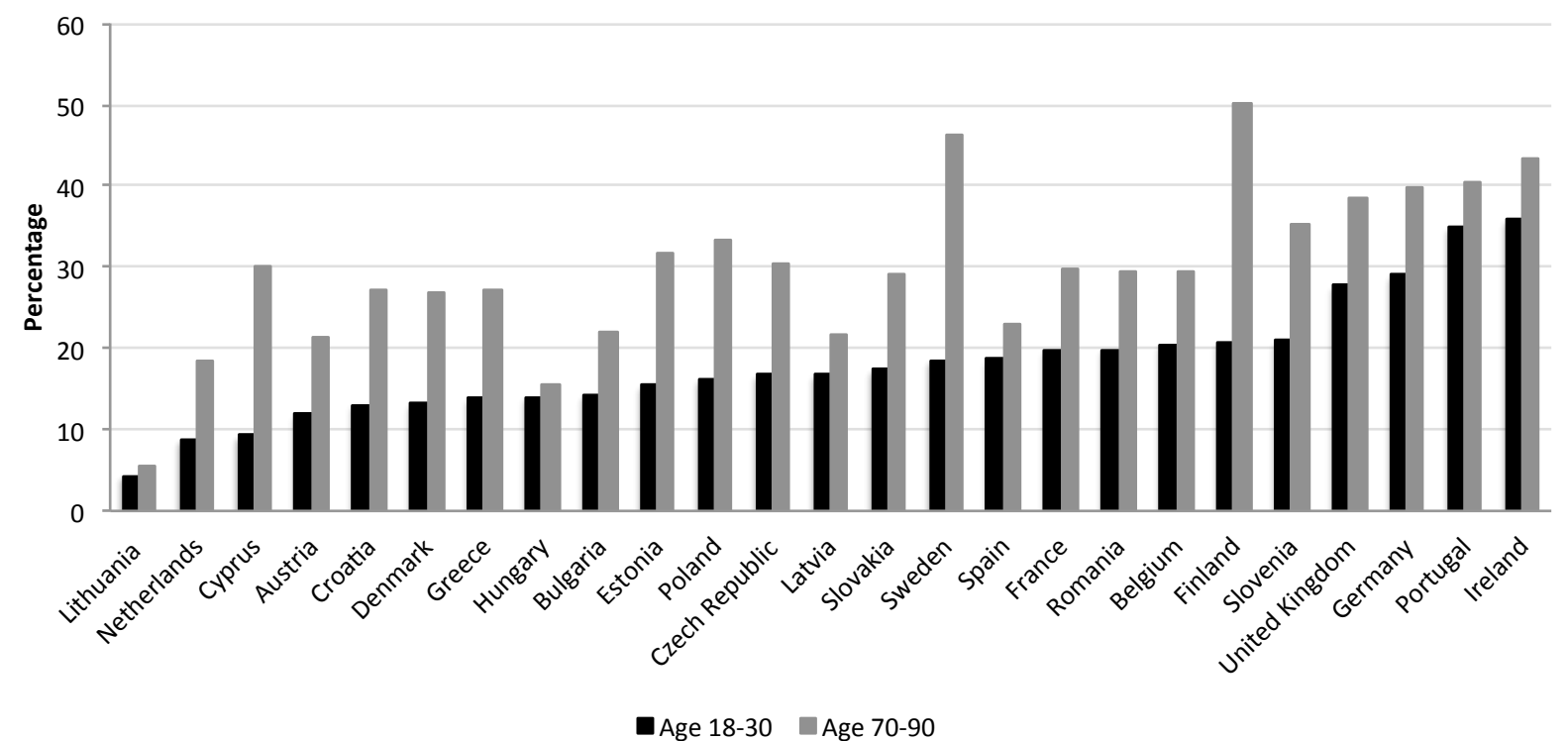

Figure 2. Prevalence of ageism, 25 EU countries.

\section{Ageism score}

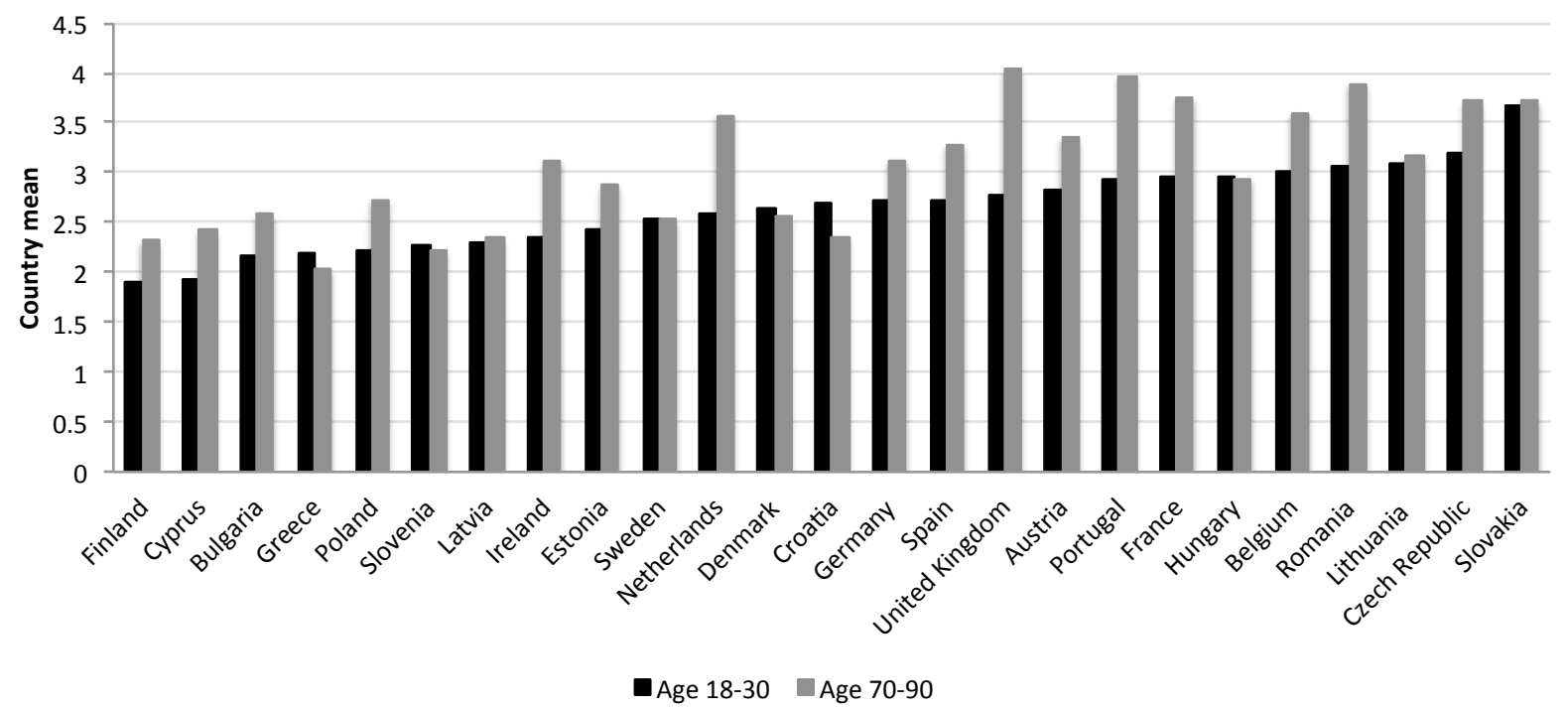


Table 1. Pearson's correlations between Active Ageing indicators and country-aggregated measures of settings enabling cross-age interaction $(\mathrm{N}=25)$.

\begin{tabular}{|c|c|c|c|c|c|c|c|c|c|c|}
\hline & \multicolumn{5}{|c|}{ Age $18-30(\mathrm{~N}=8716)$} & \multicolumn{5}{|c|}{ Age $70-90(\mathrm{~N}=6697)$} \\
\hline & $\begin{array}{l}\text { Househol } \\
\text { d member } \\
>70\end{array}$ & $\begin{array}{l}\text { Family } \\
\text { member } \\
>70\end{array}$ & $\begin{array}{l}\text { Religious } \\
\text { organi- } \\
\text { zation }\end{array}$ & $\begin{array}{l}\text { Paid or } \\
\text { volunteer } \\
\text { work }\end{array}$ & $\begin{array}{l}\text { Colleagues } \\
\text { or } \\
\text { volunteers } \\
>70\end{array}$ & $\begin{array}{l}\text { Househol } \\
\text { d member } \\
<30\end{array}$ & $\begin{array}{l}\text { (Grand-) } \\
\text { child }\end{array}$ & $\begin{array}{l}\text { Religious } \\
\text { organi- } \\
\text { zation }\end{array}$ & $\begin{array}{l}\text { Paid or } \\
\text { volunteer } \\
\text { work }\end{array}$ & $\begin{array}{l}\text { Colleagues } \\
\text { or } \\
\text { volunteers } \\
<30\end{array}$ \\
\hline AAI: Overall & $-0.68^{*}$ & $0.44 *$ & $-0.42 *$ & $0.74 *$ & $0.45^{*}$ & $-0.54 *$ & $-0.43^{*}$ & -0.25 & $0.77 *$ & $0.59 *$ \\
\hline $\begin{array}{l}\text { AAI: } \\
\text { Employment } \\
\text { AAI: }\end{array}$ & -0.29 & -0.15 & -0.17 & 0.23 & 0.13 & -0.30 & -0.17 & -0.10 & 0.23 & 0.07 \\
\hline $\begin{array}{l}\text { Participation } \\
\text { in society } \\
\text { AAI: }\end{array}$ & -0.36 & $0.41 *$ & $-0.44^{*}$ & $0.51 *$ & 0.22 & -0.38 & -0.33 & $-0.52 *$ & $0.70^{*}$ & $0.56^{*}$ \\
\hline $\begin{array}{l}\text { Independent, } \\
\text { healthy and } \\
\text { secure living }\end{array}$ & $-0.63 *$ & $0.61 *$ & -0.37 & $0.73 *$ & $0.44 *$ & $-0.46^{*}$ & -0.39 & -0.27 & $0.81 *$ & $0.64 *$ \\
\hline $\begin{array}{l}\text { AAI: Capacity } \\
\text { and enabling } \\
\text { environment }\end{array}$ & $-0.52 *$ & $0.62 *$ & -0.38 & $0.77 *$ & $0.52 *$ & -0.38 & $-0.52 *$ & -0.33 & $0.78 *$ & $0.56^{*}$ \\
\hline
\end{tabular}


Table 2. Multilevel logistic regression analysis predicting having at least two cross-age friendships. Individual-level predictors.

\begin{tabular}{|c|c|c|c|c|}
\hline & \multicolumn{2}{|c|}{ Age $18-30(\mathrm{~N}=8716)$} & \multicolumn{2}{|c|}{ Age $70-90(\mathrm{~N}=6697)$} \\
\hline & $\begin{array}{l}\text { Baseline } \\
\text { model } \\
\text { OR }\end{array}$ & $\begin{array}{c}\text { Individual- } \\
\text { level predictors } \\
\text { OR }\end{array}$ & $\begin{array}{c}\text { Baseline } \\
\text { model } \\
\text { OR }\end{array}$ & $\begin{array}{c}\text { Individual- } \\
\text { level predictors } \\
\text { OR }\end{array}$ \\
\hline $\begin{array}{l}\text { Has household member }>70 \\
{[<30]}\end{array}$ & & $1.379^{*}$ & & 1.350 \\
\hline $\begin{array}{l}\text { Discusses personal issues with } \\
\text { family member }>70 \text { [with } \\
\text { (grand)child] }\end{array}$ & & $1.689^{* * *}$ & & $1.127^{*}$ \\
\hline $\begin{array}{l}\text { Attends religious services at } \\
\text { least monthly }\end{array}$ & & $1.640^{* * * *}$ & & $1.381^{* * *}$ \\
\hline $\begin{array}{l}\text { Did paid or volunteer work } \\
\text { past month }\end{array}$ & & 1.068 & & $1.394^{* *}$ \\
\hline $\begin{array}{l}\text { Worked with colleagues or } \\
\text { volunteers in their } 70 \mathrm{~s} \text { [20s] }\end{array}$ & & $2.720^{* * *}$ & & $2.066^{* * *}$ \\
\hline Gender $($ female $=1)$ & & $0.815^{* * *}$ & & $0.782^{* * *}$ \\
\hline Age & & 1.005 & & $0.967^{* * *}$ \\
\hline Lives with partner & & $1.228^{* *}$ & & $1.200^{* *}$ \\
\hline Health status & & 0.932 & & $1.320^{* * *}$ \\
\hline Between level var. $\left(\sigma_{u}^{2}\right)$ & 0.239 & 0.257 & 0.260 & 0.264 \\
\hline Within level var. $\left(\sigma_{\mathrm{e}}^{2}\right)$ & 3.283 & 3.293 & 3.288 & 3.292 \\
\hline Intra- class correlation & 0.068 & 0.072 & 0.073 & 0.074 \\
\hline
\end{tabular}

Note. Exponentiated coefficients (Odd's ratios); ${ }^{*} p<.05,{ }^{* *} p<.01,{ }^{* * *} p<.001$ 
Table 3. Multilevel logistic regression analysis predicting having at least two cross-age friendships. Macro-level predictors.

\begin{tabular}{|c|c|c|c|c|c|c|c|c|}
\hline \multirow[b]{3}{*}{ Macro only } & \multicolumn{4}{|c|}{ Age $18-30(\mathrm{~N}=8716)$} & \multicolumn{4}{|c|}{ Age $70-90(\mathrm{~N}=6697)$} \\
\hline & OR & $\begin{array}{l}\text { Between- } \\
\text { level } \\
\text { variance } \\
\left(\sigma_{\mathrm{u}}^{2}\right) \\
\end{array}$ & $\begin{array}{c}\text { Within-level } \\
\text { variance } \\
\left(\sigma_{\mathrm{e}}^{2}\right)\end{array}$ & $\begin{array}{l}\text { Intra- class } \\
\text { correlation }\end{array}$ & OR & $\begin{array}{l}\text { Between- } \\
\text { level } \\
\text { variance } \\
\left(\sigma_{u}^{2}\right)\end{array}$ & $\begin{array}{c}\text { Within - } \\
\text { level } \\
\text { variance } \\
\left(\sigma_{\mathrm{e}}^{2}\right) \\
\end{array}$ & $\begin{array}{l}\text { Intra- class } \\
\text { correlation }\end{array}$ \\
\hline & & & & & & & & \\
\hline Baseline model & & 0.239 & 3.283 & 0.068 & & 0.260 & 3.288 & 0.073 \\
\hline AAI: Overall & 1.018 & 0.220 & 3.288 & 0.063 & $1.031^{*}$ & 0.203 & 3.291 & 0.058 \\
\hline AAI: Employment & 1.010 & 0.233 & 3.291 & 0.066 & 1.021 & 0.235 & 3.291 & 0.067 \\
\hline $\begin{array}{l}\text { AAI: Participation in } \\
\text { society }\end{array}$ & 1.003 & 0.239 & 3.293 & 0.068 & 1.010 & 0.255 & 3.292 & 0.072 \\
\hline $\begin{array}{l}\text { AAI: Independent, } \\
\text { healthy and secure living }\end{array}$ & 1.018 & 0.218 & 3.288 & 0.062 & $1.029^{*}$ & 0.204 & 3.294 & 0.058 \\
\hline $\begin{array}{l}\text { AAI: Capacity to } \\
\text { actively age }\end{array}$ & 1.014 & 0.227 & 3.292 & 0.064 & $1.024^{*}$ & 0.222 & 3.294 & 0.063 \\
\hline $\begin{array}{l}\text { Macro, controlling for } \\
\text { individual level }\end{array}$ & & & & & & & & \\
\hline AAI: Overall & 1.017 & 0.239 & 3.298 & 0.068 & 1.021 & 0.239 & 3.293 & 0.068 \\
\hline AAI: Employment & 1.013 & 0.247 & 3.292 & 0.070 & 1.020 & 0.240 & 3.286 & 0.068 \\
\hline $\begin{array}{l}\text { AAI: Participation in } \\
\text { society }\end{array}$ & 1.002 & 0.257 & 3.293 & 0.072 & 1.004 & 0.263 & 3.284 & 0.074 \\
\hline $\begin{array}{l}\text { AAI: Independent, } \\
\text { healthy and secure living }\end{array}$ & 1.015 & 0.241 & 3.283 & 0.068 & 1.019 & 0.242 & 3.292 & 0.069 \\
\hline $\begin{array}{l}\text { AAI: Capacity to } \\
\text { actively age }\end{array}$ & 1.011 & 0.249 & 3.293 & 0.070 & 1.013 & 0.254 & 3.289 & 0.072 \\
\hline
\end{tabular}

Note: Exponentiated coefficients (Odds ratio's); ${ }^{*} p<0.05,{ }^{* *} p<0.01,{ }^{* * *} p<0.001$ 
Table 4. Multilevel linear regression analysis predicting ageism. Individual-level predictors.

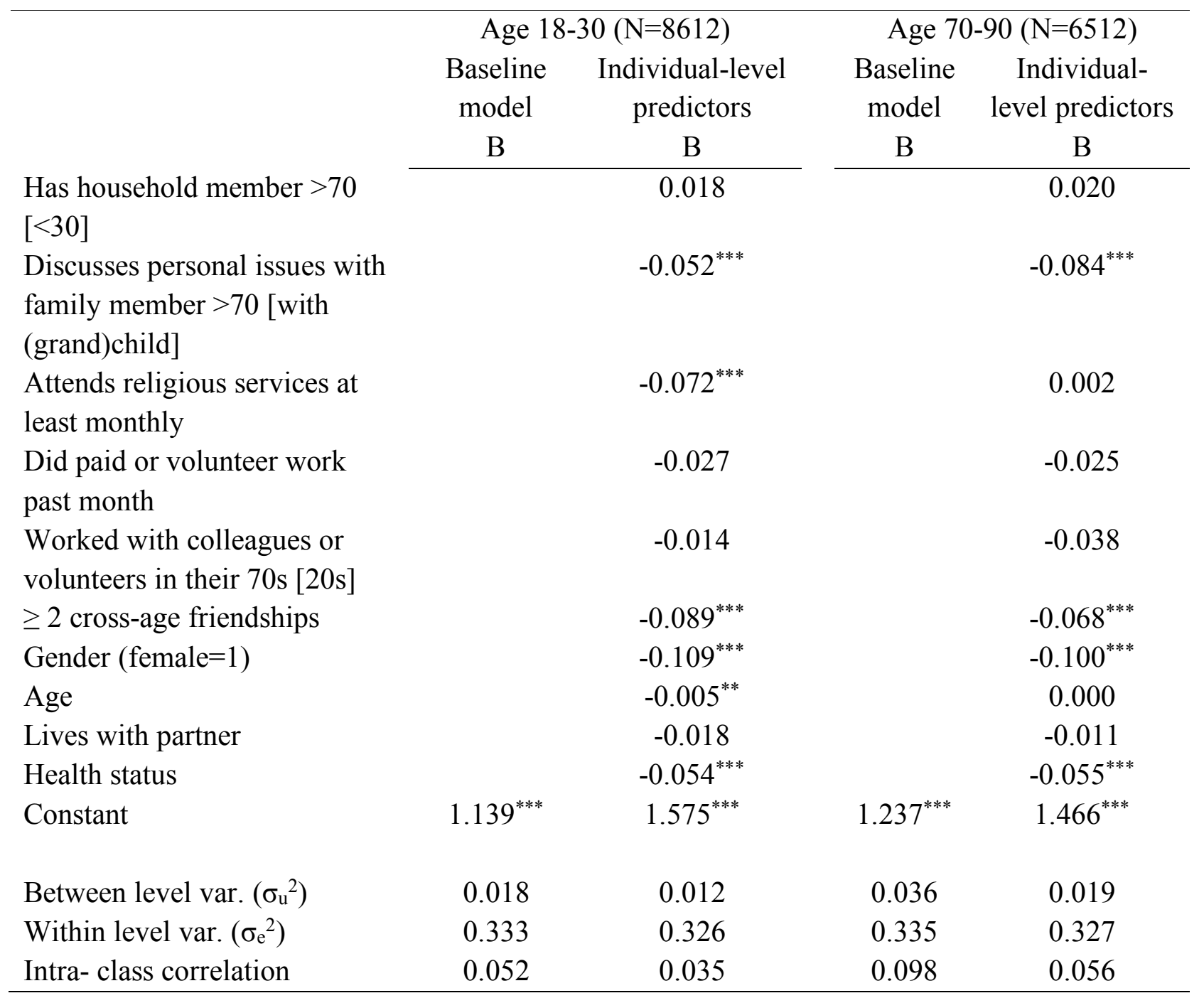

Note. ${ }^{*} p<.05, * * p<.01, * * * p<.001$ 